\title{
Naturally induced humoral response against Plasmodium vivax reticulocyte binding protein $2 \mathrm{P} 1$
}

\author{
Jenni Hietanen ${ }^{1}$, Anongruk Chim-ong ${ }^{1}$, Jetsumon Sattabongkot ${ }^{2}$ and Wang Nguitragoo I $^{*}$ (i)
}

\begin{abstract}
Background: Plasmodium vivax is the most prevalent malaria parasite in many countries. A better understanding of human immunity to this parasite can provide new insights for vaccine development. Plasmodium vivax Reticulocyte Binding Proteins (RBPs) are key parasite proteins that interact with human proteins during erythrocyte invasion and are targets of the human immune response. The aim of this study is to characterize the human antibody response to RBP2P1, the most recently described member of the RBP family.
\end{abstract}

Methods: The levels of total lgG and IgM against RBP2P1 were measured using plasmas from 68 P. vivax malaria patients and 525 villagers in a malarious village of western Thailand. The latter group comprises asymptomatic carriers and healthy uninfected individuals. Subsets of plasma samples were evaluated for anti-RBP2P1 IgG subtypes and complement-fixing activity.

Results: As age increased, it was found that the level of anti-RBP2P1 IgG increased while the level of IgM decreased. The main anti-RBP2P1 IgG subtypes were $\lg G 1$ and $\lg G 3$. The $\lg G 3$-seropositive rate was higher in asymptomatic carriers than in patients. The higher level of IgG3 was correlated with higher in vitro RBP2P1-mediated complement fixing activity.

Conclusions: In natural infection, the primary $\lg G$ response to RBP2P1 was $\lg G 1$ and $\lg G 3$. The predominance of these cytophilic subtypes and the elevated level of IgG3 correlating with complement fixing activity, suggest a possible role of anti-RBP2P1 antibodies in immunity against $P$. vivax.

Keywords: Plasmodium vivax, Malaria, Cytophilic, Complement, Antibody, Serology

\section{Background}

Plasmodium vivax malaria remains a major public health problem in many countries. At present, there is no approved vaccine for $P$. vivax, but such a vaccine would be highly useful for the global malaria eradication. Several types of vaccines have been considered for $P$. vivax malaria, including one to prevent or

\footnotetext{
*Correspondence: wang.ngu@mahidol.edu

${ }^{1}$ Department of Molecular Tropical Medicine and Genetics, Faculty of Tropical Medicine, Mahidol University, 420/6 Ratchawithi Road, Ratchathewi, 10400 Bangkok, Thailand

Full list of author information is available at the end of the article
}

eliminate liver stage infection (pre-erythrocytic vaccine), one to reduce blood stage parasitaemia (blood stage vaccine), and one to block transmission from humans to mosquitoes (transmission-blocking vaccine). Blood stage vaccines are aimed to neutralize red cell infection, which is the immediate cause of malaria symptoms. Blood stage vaccines for $P$. vivax will help reduce disease transmission because the density of gametocytes, the stage transmissible to the mosquitoes, is closely linked to the total blood parasitaemia [1-3]. Several P. vivax asexual blood stage antigens have been considered for vaccine development, including Duffy binding protein (DBP) [4], 
several Reticulocyte binding proteins (RBPs) [5], apical membrane antigen 1 (AMA1), and merozoite surface proteins (MSPs) [6]. Currently the most advanced candidate is the P. vivax Duffy Binding Protein (PvDBP), which has entered Phase 1a clinical trials [7, 8]. Other targets $[5,8]$ are much further behind and new candidates are still needed to maintain a healthy vaccine development pipeline.

Plasmodium vivax RBPs are a major group of $P$. vivax invasion ligands. Human antibodies to some of these proteins have been shown to be associated with clinical protection [9-11]. Antibodies to one of them, RBP2b, directly inhibit erythrocyte invasion [12]. Recently, we characterized a novel RBP, RBP2P1, and found that a higher level of total IgG to RBP2P1 is associated with lower parasitaemia, suggesting an involvement in functional immunity [13]. However, the analysis was limited to total IgG.

This study aims to provide a more complete account of human antibody response to RBP2P1. Plasmas from acute $P$. vivax malaria patients and the general population in an endemic area in Thailand were examined for IgM, total IgG, IgG subtypes, and anti-RBP2P1 antibody-mediated complement fixing activity.

\section{Methods}

The use of human specimens in this study was approved by the Ethics Committee of the Faculty of Tropical Medicine, Mahidol University.

\section{Study sites}

Malaria transmission in Thailand is seasonal and found mainly near the country border, with Myanmar to the west, Cambodia to the east and Malaysia to the south [14-16]. The study sites, Kanchanaburi and Ratchaburi provinces, are located on the western border. Both provinces are endemic for malaria [3]. At the time of sample collection (September-October 2012), the study sites had an overall malaria prevalence of $4.18 \%$ by PCR (P. vivax $3.09 \%$, Plasmodium falciparum $0.86 \%$ and mixed P. vivax/ P. falciparum $0.26 \%$ ) [3]. In a cohort study conducted shortly thereafter (2013-2014) [17], the prevalence varied seasonally from 1.7 to $4.2 \%$ for P. vivax and $0-1.3 \%$ for P. falciparum. The infections were found primarily in a small number of individuals who were positive at multiple time points during the monthly active surveys. Most infections (90\%) were asymptomatic, as confirmed by the lack of malaria-like symptoms during the followup period.

\section{Study specimens}

During the 2012 cross-sectional study [3], plasma samples were collected from the general population and a subset of these plasma samples used in this current study. Among the volunteers, 26 had low-density $P$. vivax infection without concurrent fever (body temperature $>37.5{ }^{\circ} \mathrm{C}$ ) and no history of fever or feeling unwell within the preceding $48 \mathrm{~h}$. These 26 people were classified as asymptomatic carriers in this study. In addition to these cross-sectional survey samples, additional plasma samples were obtained from $68 P$. vivax acute malaria patients (PCR-confirmed) from the same village in 2012-2013. The summary of the study population characteristics is provided in Table 1. Seven plasma samples from unknown healthy donors from Bangkok, a non-endemic area, were obtained from the Thai Red Cross and used as the negative control for the antibody-typing assays. For the complement assay, additional 8 negative samples were obtained from the Thai Red Cross, making the total number of negative control samples 15.

\section{Expression and purification of PVRBP2-P1}

As described earlier [13], the full-length RBP2-P1 (1788 bp, signal peptide excluded) was expressed in Escherichia coli SHuffle cells as a soluble protein. The recombinant RBP2P1 protein $(70 \mathrm{kDa})$ was purified by metal affinity chromatography and, after removal of 6-His tag, further purified with FPLC.

\section{Antibody measurements}

Antibody levels were measured by using a Bioplex (Bio-Rad) bead-based assay as described [18]. Briefly, $\mathrm{COOH}$ microspheres $\left(2.5 \times 10^{6}\right.$, Luminex Corp) were washed with PBS (Phosphate Buffered Saline), incubated at room temperature for $20 \mathrm{~min}$ at constant agitation with $100 \mathrm{mM}$ monobasic sodium phosphate $(\mathrm{pH} 6.2), 50 \mathrm{mg} / \mathrm{ml}$ sulfo-NHS

Table 1 Characteristics of the 593 study volunteers from western Thailand

\begin{tabular}{llll}
\hline Parameter & Uninfected $^{\text {a }}$ & Asymptomatic $^{\text {a }}$ & Patient $^{\mathbf{b}}$ \\
\hline $\mathrm{n}$ & 499 & 26 & 68 \\
Male sex, no. (\%) & $227(46)$ & $19(73)$ & $50(74)$ \\
Age, median (range) & $20(0.8-92)$ & $35(8-70)$ & $29(18-71)$ \\
0-6 years, n & 81 & - & - \\
7-12 years, n & 98 & 2 & - \\
13-17 years, n & 48 & 4 & - \\
$18+$ years, $n$ & 272 & 20 & 68 \\
\hline
\end{tabular}

${ }^{a}$ From a cross-sectional malaria survey

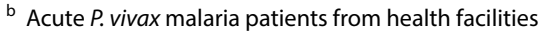


(N-hydroxysulfosuccinimide sodium salt) and $50 \mathrm{mg} / \mathrm{ml}$ of EDC [N-(3-dimethylaminopropyl)- $\mathrm{N}^{\prime}$ ethylcarbodiimide hydrochloride] to activate the amine groups on the microspheres' surface to capture the carboxyl groups of the target protein. Coupling reaction was incubated overnight at $4{ }^{\circ} \mathrm{C}$ with constant agitation. On the next day microspheres were washed with PBS-TBN (1X PBS buffer $\mathrm{pH}$ 7.4, with $0.05 \%$ Tween 20. $1 \%$ BSA, $0.1 \%$ Sodium Azide) buffer and stored in the same buffer until antibody measurements. Protein concentration used for the coupling was optimized by experimentally testing the amount of protein that would generate a log-linear standard curve using a positive control plasma pool prepared from Thai $P$. vivax patient samples.

Plasma samples were diluted $1 / 100$ when measuring IgG and $1 / 200$ for IgM detection in PBS with $1 \%$ BSA and $0.05 \%$ Tween (PBT). Each diluted plasma $(50 \mu \mathrm{l})$ was added to a 96-well Multiscreen filter plate together with $0.1 \mu \mathrm{l}$ of coupled RBP2-P1 microspheres in $50 \mu \mathrm{l}$ of PBT per well. The plate was incubated at room temperature for $30 \mathrm{~min}$ on a plate shaker. After incubation, the microspheres were washed three times with $100 \mu \mathrm{l}$ of PBT. Then, $100 \mu \mathrm{l}$ of $1 / 100$ dilution in PBT of the following IgG or IgG subtype detector antibodies were used: donkey anti-human IgG Fc-PE $(0.5 \mathrm{mg} /$ $\mathrm{ml}$, Jackson ImmunoResearch), mouse anti-human IgG1 hinge-PE $(0.1 \mathrm{mg} / \mathrm{ml}$, Southern Biotech), mouse anti-human IgG2 Fc-PE $(0.1 \mathrm{mg} / \mathrm{ml}$, Southern Biotech), mouse anti-human IgG3 hinge-PE $(0.1 \mathrm{mg} / \mathrm{ml}$, Southern Biotech) and mouse anti-human IgG4 Fc-PE $(0.1 \mathrm{mg} / \mathrm{ml}$, Southern Biotech). For IgM detection, $100 \mu \mathrm{l}$ of $1 / 400$ dilution in PBT of donkey anti-human IgM Fc5u-PE $(0.5 \mathrm{mg} / \mathrm{ml}$, Jackson ImmunoResearch) was used. Detector antibodies were incubated with the microspheres at room temperature for $15 \mathrm{~min}$ on a plate shaker. Microspheres were washed three times with $100 \mu \mathrm{l}$ of PBT and resuspended to $100 \mu \mathrm{l}$ of PBT. Fluorescence was measured with Bio-Plex $200^{\circledR}$. BioPlex $200^{\circledR}$ gave the result as the median fluorescent intensity (MFI). Each sample was standardized to the arbitrary unit (AU) by an in-plate standard curve generated by running a two-fold serial dilution (IgG: 1/50 to $1 / 25,600$ and $\operatorname{IgM} 1 / 25$ to $1 / 25,600$ ) of the positive control plasma pool from $P$. vivax patients. To determine the fluorescence background, several blank wells without plasma were run in each plate. Plasma from healthy volunteers were included as the negative control for each assay. The seropositivity threshold was set as the mean +2 standard deviations (SD) of the negative controls.

\section{Complement-fixation assay}

The complement fixation potential of anti-RBP2P1 antibodies were measured by ELISA-based assay as described earlier [19]. Briefly, Nunc Maxisorp 96-well plates were coated with $10 \mu \mathrm{g} / \mathrm{ml}$ of PvRBP2-P1 and incubated overnight at $4{ }^{\circ} \mathrm{C}$. At each step the volume added per well was $100 \mu \mathrm{l}$. Wells were blocked with $10 \%$ skim milk in PBS-Tween $(1 \mathrm{x}$ PBS $+0.01 \%$ Tween 20) for $1 \mathrm{~h}$. After blocking, wells were washed three times with PBS-Tween. Plasma samples were heatinactivated at $56{ }^{\circ} \mathrm{C}$ for $30 \mathrm{~min}$ to destroy the complement. After that, samples were diluted $1 / 100$ in $1 \%$ skim milk in PBS-Tween and were added to the plate and incubated at RT for $1 \mathrm{~h}$. Plates were washed three times with PBS-Tween. Human complement protein C1q (Merck Millipore) in 1\% skim milk and PBS-Tween was added at $10 \mu \mathrm{g} / \mathrm{ml}$ and incubated at RT for $30 \mathrm{~min}$. Plates were washed three times with PBS-Tween. 1/2000 in $1 \%$ skim milk and PBS-Tween diluted chicken anti-human $\mathrm{C} 1 \mathrm{q}$ antibody (Merck Sigma-Aldrich) was then added and incubated $1 \mathrm{~h}$ at RT. Wells were washed three times with PBS-Tween. To detect bound C1q, $1 / 4000$ in $1 \%$ skim milk and PBS-Tween diluted rabbit anti-chicken-IgY-(IgG)-HRP (Merck Sigma-Aldrich) was added and incubated for $1 \mathrm{~h}$. Wells were washed three times with PBS-Tween and then finally three times with PBS. Detection of C1q fixation was done by incubating with ABTS (Merck Millipore) for $30 \mathrm{~min}$ and absorbance quantified by using a plate reader. OD values were normalized against a positive control sample (a P. vivax patient plasma) and reported as AU. This control sample was used on all plates to permit comparison of data across different plates.

\section{Statistical analysis}

MFI values were converted to relative antibody units. Further analysis and data presentation was performed in Prism version 6 (GraphPad, USA) or PASW Statistics version 18.0.0. Differences in the antibody levels between groups of different infection status were compared by using the Kruskal-Wallis test with Dunn's multiple-comparison test and data are presented using box-plots, with error bars showing the 5-95 percentile range and dots representing the outliers. Differences in seroprevalence between age groups or groups of different infection status was tested with the Fisher's exact test. Spearman's rank correlation was used to determine correlation between parameters as specified in the text. 

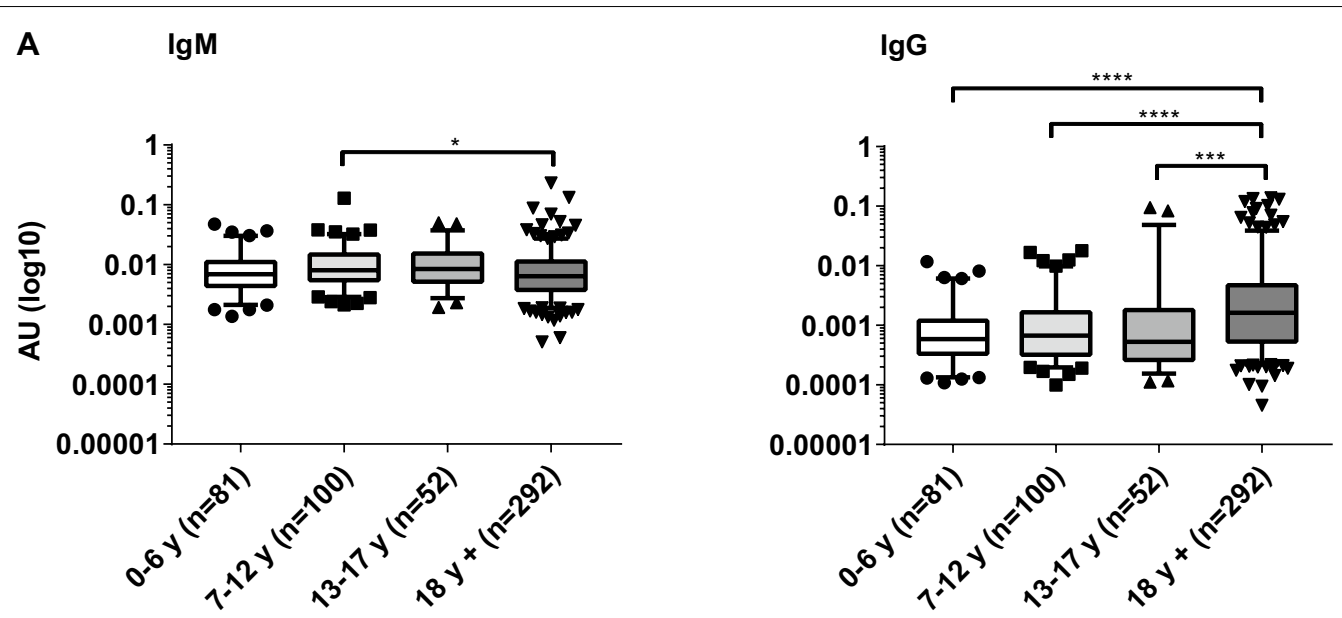

B $\quad \lg M$

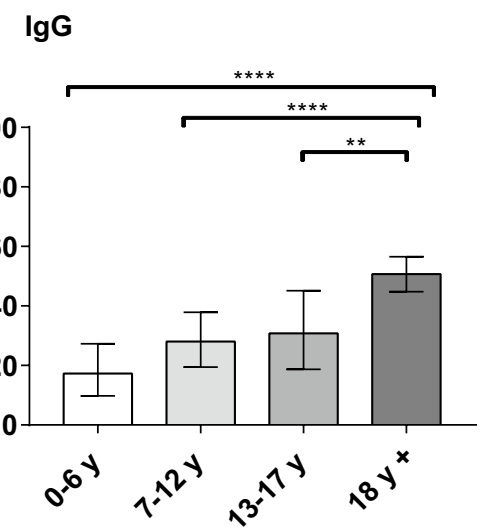

Fig. 1 IgM and IgG responses in a cross-sectional survey: A Antibody levels. Box-plots represent the median and the interquartile range; error bars indicate the 5-95 percentiles; filled symbols represent outliers. Differences in the antibody levels between the age groups were analyzed with Kruskal-Wallis test with Dunn's multiple-comparison test. B Seropositive rates. Bars represent the proportions of IgM and IgG seropositive individuals in the different age groups. The seropositive cut off values (mean +2 SD) for antibody types were: $\operatorname{lgM} 8.82 \times 10^{-3}$ and $\operatorname{lgG} 9.32 \times 10^{-4}$. Error bars indicate $95 \%$ confidence intervals. Differences between the groups were analyzed with Fisher's exact test. ${ }^{* * *} p<0.0001,{ }^{* * *} p<0.001,{ }^{* *} p<0.01$, ${ }^{*} p<0.05$

\section{Results}

\section{IgM and total IgG in the community survey}

525 plasma samples from a cross-sectional survey in Kanchanaburi province were used to examine the presence of RBP2P1 antibodies in the community. The age of the study participants showed a positive correlation with total IgG (Spearman $\rho=0.317, p=0.01$ ), but a negative correlation with IgM (Spearman $\rho=-0.144$, $\mathrm{p}=0.001$ ). When the cross-sectional samples were classified into four age groups: $0-6$ years, $7-12$ years, $13-17$ years and $\geq 18$ years, the anti-RBP2P1 IgM levels were higher (Kruskal-Wallis test with Dunn's multiple-comparison test, $\mathrm{p}=0.0168$ ) in children aged 7-12 years compared to adults (Fig. 1A). The IgG response (Fig. 1A) was higher in the adult group compared with all younger groups $(\mathrm{p}<0.001)$. Consistently, IgG seropositivity in the adult group was higher compared to the other three groups (Fisher's exact test, $\mathrm{p}<0.01$ for all pairwise comparison) (Fig. 1B). There were no significant differences among the age groups for IgM seropositivity (Fisher's exact test, $\mathrm{p}>0.05$ for all pairwise comparison) (Fig. 1B).

\section{Comparison between $P$. vivax asymptomatic carriers, patients, and uninfected individuals}

34 $P$. vivax malaria patients and 31 selected individuals from the cross-sectional survey (22 asymptomatic P. vivax carriers +9 healthy parasite-free villagers who reported never to have had malaria) were selected for further comparative analysis. The patient specimens 
were obtained from the malaria clinic in the study village at roughly the same time period (2012-2013). The plasma samples were tested for anti-RBP2P1 IgM, total IgG, IgG1, IgG2, IgG3 and IgG4.

The median of anti-RBP2P1 IgM levels in P. vivax patients did not differ from that of asymptomatic carriers, but it was higher than that of uninfected villagers or healthy Bangkok donors (Fig. 2A). A similar pattern was found for total IgG (Fig. 2A) as well as IgG1 and IgG3 (Fig. 2B). No statistically significant difference was detected between the four groups for IgG2 (Fig. 2B). IgG4 was not detected in any sample.

The anti-RBP2P1 seropositive rates in asymptomatic carriers, patients, and uninfected villagers were also compared. The mean $+2 S D$ value of the Bangkok donors was used as the seropositivity threshold. There was no difference in the seropositive rates between the three groups for IgM (Fig. 3A). For total IgG, the seropositive rates were similar between the patients $(94 \%)$ and the asymptomatic carriers $(91 \%)$. Both groups had a higher seropositive rate than the uninfected villagers did $(0 \%)$ (Fisher`s exact test, $\mathrm{p}<0.0001$ ) (Fig. 3A). IgG1 seropositivity followed a similar trend (patients $44 \%$ and asymptomatic carriers $59 \%$ ), albeit at lower rates in the two infected groups (Fig. 3B). For IgG2, the seropositive rates were low and indistinguishable in all three groups. For IgG3, the seropositive rate was higher in the asymptomatic carriers $(95 \%)$ compared to the patients $(68 \%)$ (Fisher exact test, $\mathrm{p}=0.0183$ ), who in turn, had a higher seropositive rate than the uninfected villagers (22\%) (Fisher's exact test, $\mathrm{p}=0.0226)($ Fig. 3B).

\section{RBP2P1-mediated complement fixation}

The complement-fixing activities of anti-RBP2P1 antibodies were assessed. The same subpopulation of 22 asymptomatic carriers, 34 patients, and 9 uninfected villagers used for IgG subtyping were subjected to an ELISA-based complement fixation assay (Fig. 4). A set of 15 healthy Bangkok donors were also used as the control. This assay infers the complement fixing activity from the ability of antiRBP2P1 antibodies to bind human C1q, the first step of the classical complement pathway. Because the asymptomatic and patient groups have indistinguishable complement-fixing activity (data not shown), they were combined into a single $P$. vivax 'infected' group (Fig. 4). This group had significantly higher level of complement-fixing activity than the uninfected villagers and the Bangkok donors (KruskalWallis test with Dunn's multiple-comparison test, $\mathrm{p}=0.0001$ and $\mathrm{p}=0.0002$, respectively) (Fig. 4).

To test whether the higher complement-fixing activity in the $P$. vivax infected individuals $(\mathrm{n}=56)$ is associated with IgM and cytophilic antibodies, correlation analysis was performed (Fig. 5). The results show that the levels of IgG1 and IgG3 subtypes, but not IgM, were rank-correlated with complement-fixing activity (Spearman's rank correlation, $\mathrm{p} \leq 0.011$ ). In a multivariate linear regression model using IgM, IgG1, and IgG3 as independent variables, only IgG3 remains significantly associated with complementfixing activity $(\mathrm{p}=0.018)$.

\section{Discussion}

Naturally acquired antibodies are important factors in protective immunity against malaria [20, 21]. Many merozoite antigens are natural immunogens and actively being pursued as vaccine targets. For $P$. falciparum blood-stage vaccines, several targets, including AMA1, EBA175, GLURP, MSP1, MSP2 and MSP3, have reached clinical trials, and more recent candidates such as reticulocyte-binding protein homolog 5 (PfRh5) are under active research [7, 22]. For the blood stage $P$. vivax vaccine, DBP has been the sole intensively studied candidate [7]. Over the past five years $P$. vivax RBPs have garnered increasing attention as functional invasion ligands of the parasite, markers of exposure, and vaccines candidates [5, 12, 23, 24]. Two members of the family, RBP1a and RBP2b, appear promising for further vaccine development [5]. RBP2P1 is the most recently characterized member of the RBP family [13]. Its small size of $72 \mathrm{kDa}$ allows the nearly full-length recombinant protein expression [13]. Compared to the other members, the antibody response to RBP2P1 has been less well investigated.

In this study, the naturally acquired antibody responses to RBP2P1 among villagers living in a $P$. vivax endemic area of western Thailand were measured. Although the transmission intensity in the study

(See figure on next page.)

Fig. 2 Anti-RBP2P1 lgM, lgG and lgG subtype responses in different types of donors. A IgM and lgG responses of a subset of the cross-sectional survey samples (asymptomatic carriers and uninfected villagers), patients and Bangkok donors. B lgG1, lgG2 and lgG3 responses in the same four groups. Box-plots represent the median and the interquartile range; error bars indicate the 5-95 percentiles; filled symbols represent outliers. ${ }^{* * * *} p<0.0001,{ }^{* * *} p<0.001,{ }^{* *} p<0.01,{ }^{*} p<0.05$ (Kruskal-Wallis test with Dunn's multiple-comparisons test) 
A

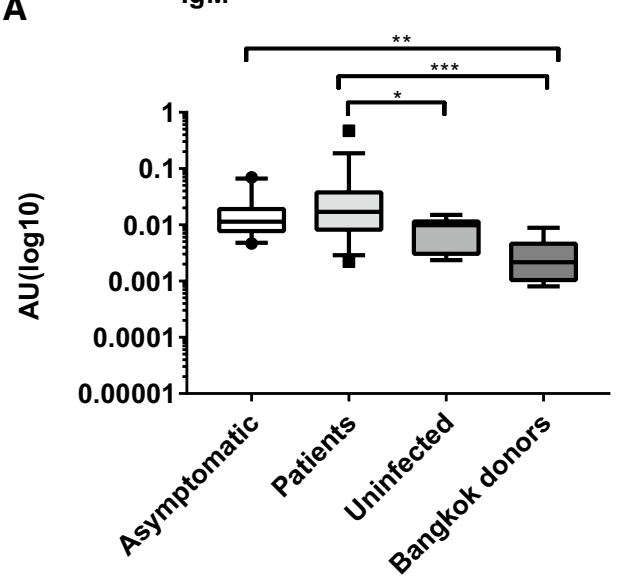

B

IgG1

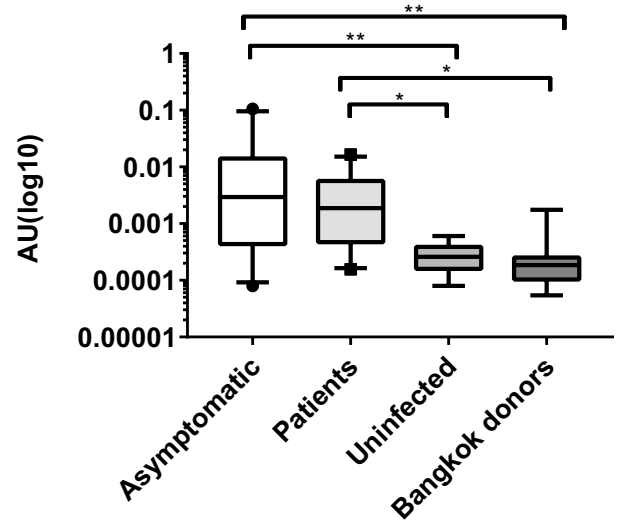

C

$\lg G 3$

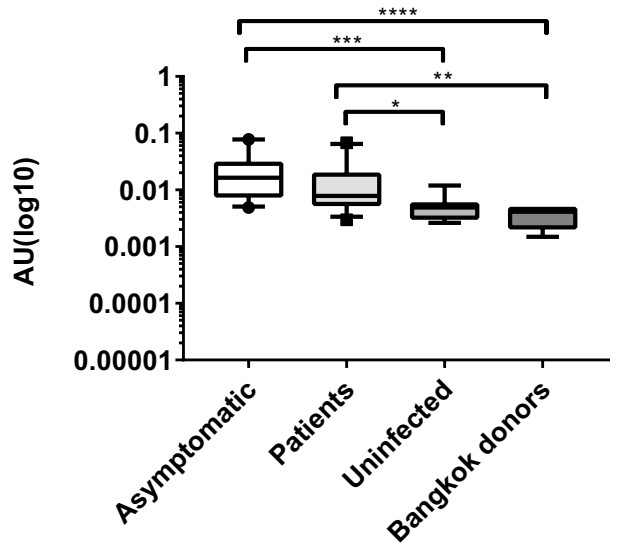

IgG

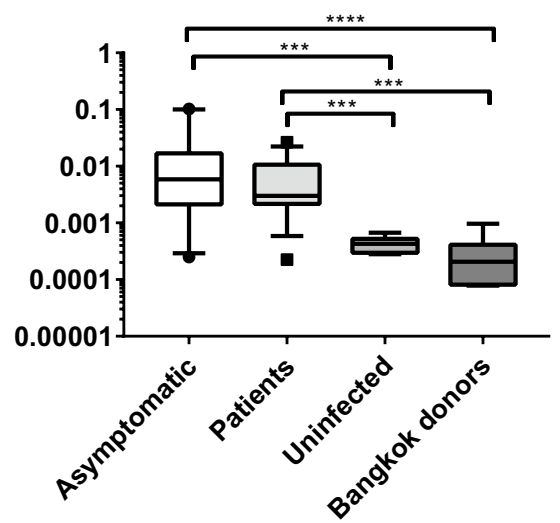

IgG2

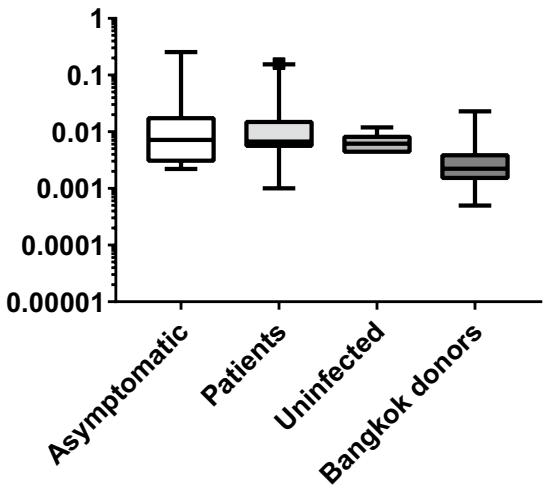



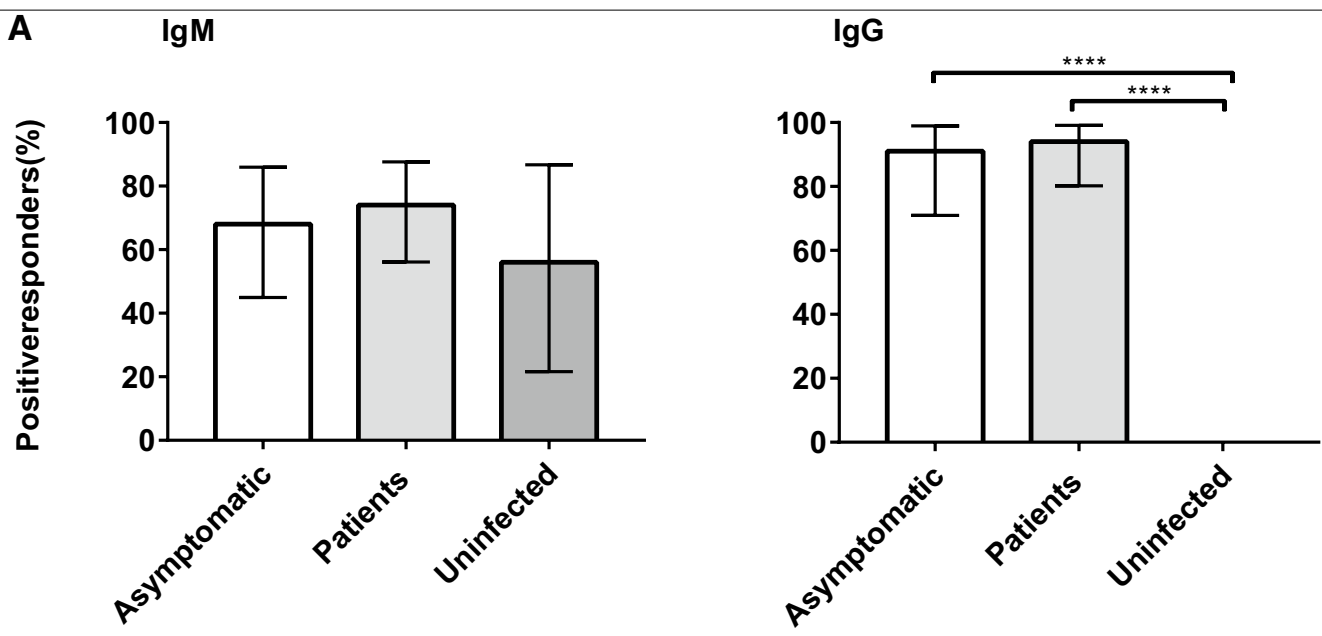

B $\quad \lg G 1$

$\lg G 2$
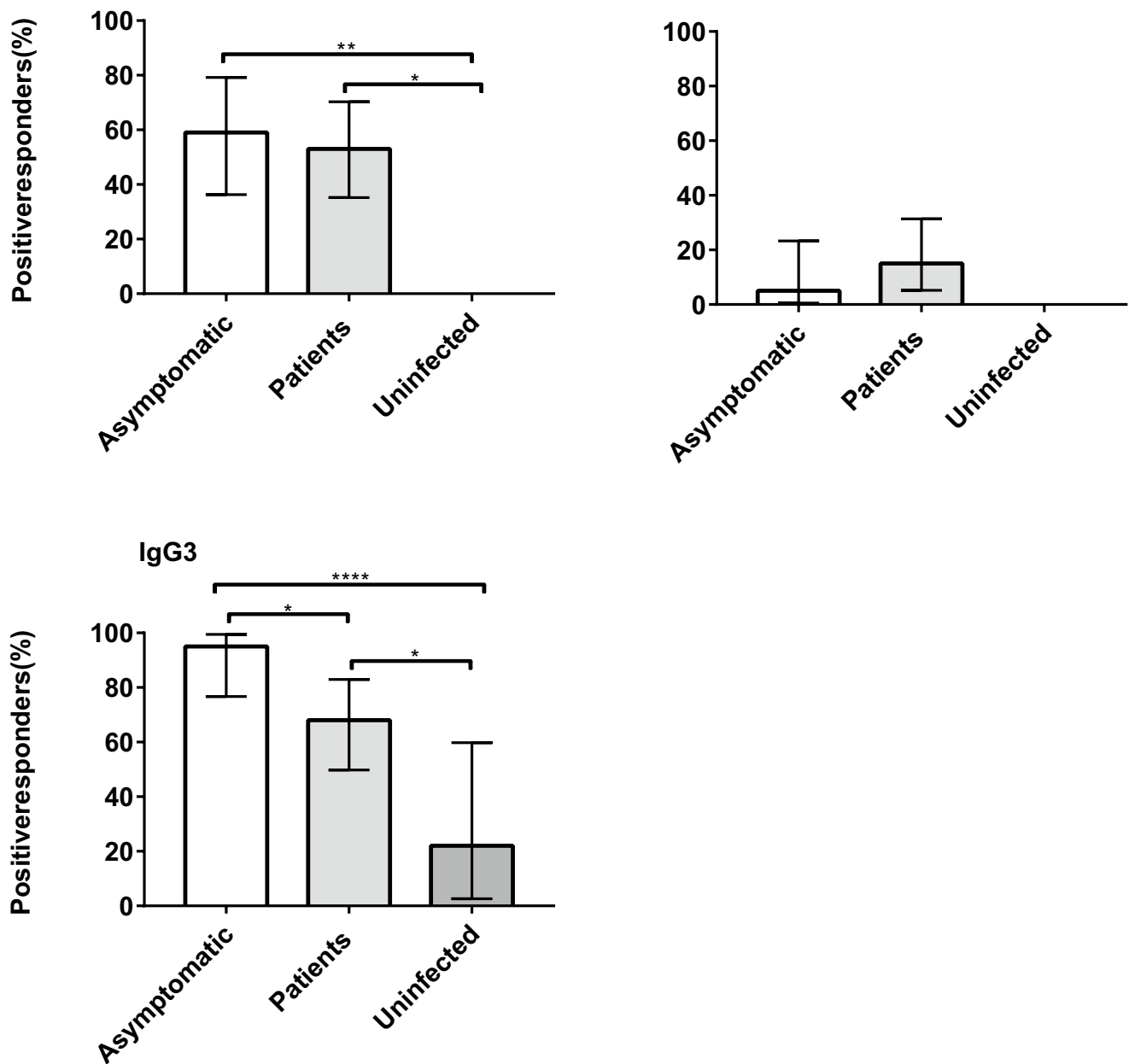

Fig. 3 Anti-RBP2P1 seropositivity rates in different types of villagers. A IgM and IgG seropositivity rates in P. vivax asymptomatic carriers, patients, and uninfected villagers. The seropositive cut off values (mean+2SD) for antibody types were: $\operatorname{lgM} 8.82 \times 10^{-3}$ and $\operatorname{lgG} 9.32 \times 10^{-4}$. B IgG1, IgG2 and $\lg$ G3 seropositivity rates in the same three groups. The seropositive cut off values for antibody types were: IgG1 $1.60 \times 10^{-3}, \mathrm{IgG} 22.01 \times 10^{-2}$ and lgG3 $4.89 \times 10^{-3}$. Error bars indicate the $95 \%$ confidence intervals. ${ }^{* * *} p<0.0001,{ }^{* * *} p<0.001,{ }^{* *} p<0.01,{ }^{*} p<0.05$ (Fisher's exact test) 
site in Thailand was low ( $3.1 \%$ P. vivax prevalence by qPCR), several villagers still had protective immunity as they could carry the parasite without becoming sick $[3,17]$. In this population, the IgM response showed a weak negative correlation with age. In addition, IgG tended to increase with age, similar to trends observed with many $P$. vivax antigens [18, 25-27]. These correlations presumably reflect the maturation of the host immune system from the IgM to the more specific IgG, after IgG memory being boosted over time by repeated exposures [28, 29].

In the adult group, only $7 \%$ had ongoing $P$. vivax infection yet nearly half (48\%) were seropositive for RBP2P1 (Fig. 1C, D). Although the majority of P. vivax antigens were reported to have a half-life of less than 6 months [23], there is evidence of long-living antibodies, with PvMSP1 lasting from a year to 30 years and PvMSP8 from 8 to 12 years [30-35]. According to the antibody half-life model from Longley and coworkers who measured the antibody half-lives of over 300 $P$. vivax antigens, the estimated half-life of RBP2P1 antibodies is fairly long at 308 (95\% CI, 218-521) days [24]. Thus, in addition to recent exposure, the long half-life may contribute to the high anti-RBP2P1 IgG seropositivity rate among the uninfected villagers.

The major IgG subtypes reactive to RBP2P1 were IgG1 and IgG3. This is similar to an earlier report for PvRBP1a and PvDBP [11]. The function of cytophilic antibody subtypes IgG1 and IgG3 may extend beyond interfering with red blood cell binding $[13,20]$ to encompass other effectors functions, such as opsonic phagocytosis [36], antibody-dependent cellular inhibition [37], and complement activation through binding to the C1q protein complex [38]. Between the two cytophilic subtypes, IgG3 is known to have a higher complement fixing potential [38]. We found that the IgG3 seropositivity was higher in asymptomatic carriers than in patients, paralleling the ability of the former groups to control the parasitaemia at a very low level.

Previous studies have reported similar linkage between elevated IgG3 levels against merozoite antigens and protection from clinical symptoms, such as for $P$. falciparum MSP2, MSP3, AMA1, GLURP, EBA175 and $P$. vivax DBP, MSP1 and GAMA [39-43]. However, due to the nature of the cross-sectional study, it remains inconclusive whether IgG3 is responsible for the clinical protection. An analysis of a cohort from an endemic area would provide a clearer answer.

It has become evident that the optimal antigen to be used for malaria vaccine development should not solely trigger the maximum antibody titers, but that

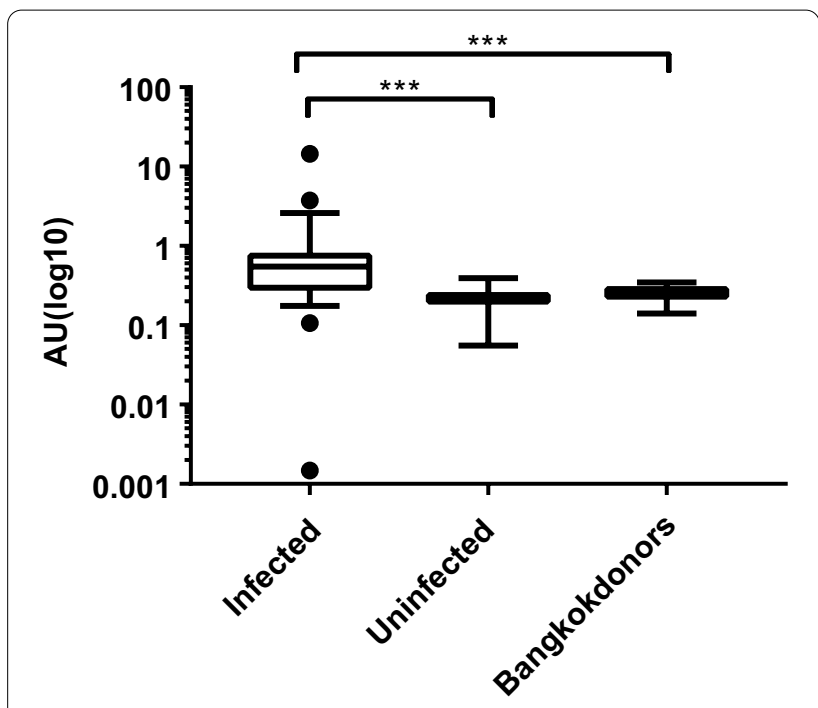

Fig. 4 Complement-fixing (C1q-binding) activity of different types of donor plasmas. Box-plots represent the median and the interquartile range; error bars indicate the 5-95 percentiles; filled symbols represent outliers. Filled symbols represent outliers. ${ }^{* * * *} p<0.0001,{ }^{* * *} p<0.001,{ }^{* *} p<0.01,{ }^{*} p<0.05$ (Kruskal-Wallis test with Dunn's multiple-comparisons test)

these antibodies should also have a function [38]. New tests are needed to assess antibody's functional properties because the traditional growth inhibition assay does not always predict the protection gained by natural infection or vaccine induced immunity $[8,19]$. Additional assays are particularly important with $P$. vivax, which cannot be cultured, making it challenging to test most interventions. The recently developed complement-fixation assay is a useful tool to test whether antibodies against malaria antigens are able to fix the complement, leading to complement-mediated killing of the parasites [19]. Several P. falciparum antigens have been identified as targets of complementfixing antibodies [19, 44]. Of particular interest is circumsporozoite protein PfCSP, the most prominent malaria vaccine target. The major antibody types targeting PfCSP were IgM and cytophilic antibodies IgG1 and IgG3, and they all were able to fix complement in the classical pathway [44]. Only one P. vivax antigen, Merozoite Surface Protein $3 \alpha$ (PvMSP $3 \alpha$ ), has been subjected to the complement-fixing assay. RBP2P1 is the second target evaluated [45]. With PvMSP3 $\alpha$ both cytophilic subtypes, IgG1 and IgG3 as well as IgM showed correlation with complement fixation similar to PfCSP [45]. For RBP2P1, IgG3 has the most robust correlation with complement fixation. 
$\lg M$

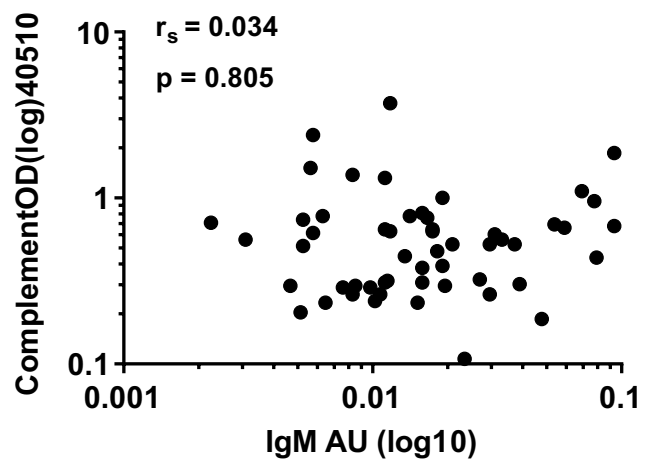

$\lg$ G3

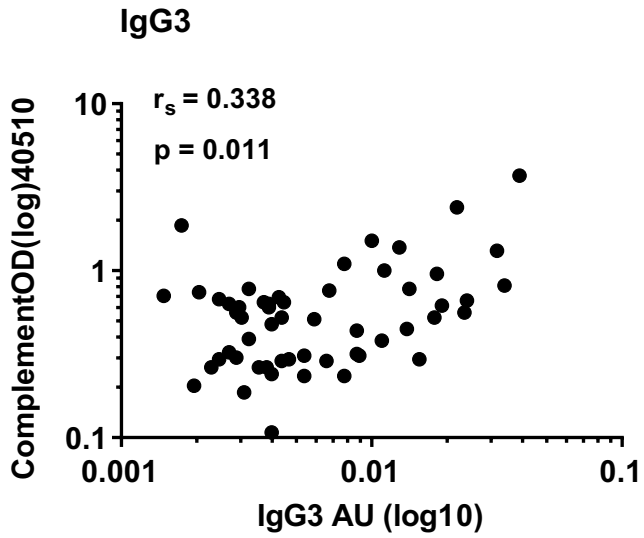

$\lg \mathbf{1} 1$

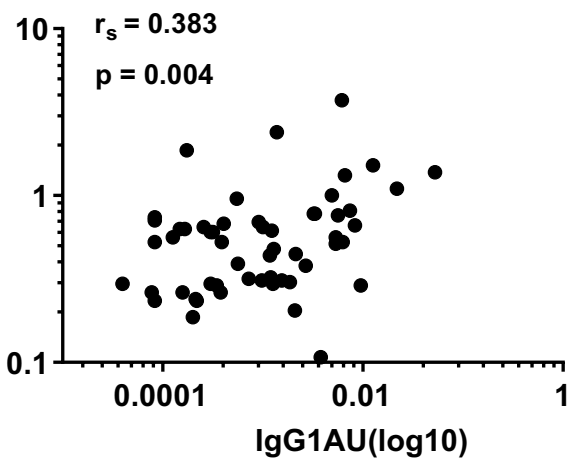

Fig. 5 Complement-fixing activity correlates with the lgG1 and lgG3 levels. Antibody levels in arbitrary units (AU) of infected individuals are plotted as a function of complement-fixing (C1q-binding) activity $(n=56)$. $r_{s^{\prime}}$ Spearman's rank correlation

\section{Conclusions}

The naturally-acquired humoral immune response against $P$. vivax merozoite protein RBP2P1 is biased towards cytophilic antibodies IgG1 and IgG3. The IgG3 seropositivity rate against RBP2P1 was higher in asymptomatic $P$. vivax carriers than in clinical $P$. vivax malaria patients. The level of IgG3 antibody subtype was correlated with complement fixation activity, suggesting that RBP2P1 is a target of functional human immune response to $P$. vivax infection.

\section{Abbreviations}

RBP: Reticulocyte binding protein.; Sulfo-NHS: N-hydroxysulfosuccinimide sodium salt.; EDC: $N$-(3-dimethylaminopropyl)-N'-ethylcarbodiimide hydrochloride.; FPLC: Fast protein liquid chromatography.; PBT: Phosphate buffered saline containing $1 \%$ bovine serum albumin and $0.05 \%(\mathrm{v} / \mathrm{v})$ Tween-20.; MFI: Median fluorescent intensity.

\section{Acknowledgements}

We are indebt to Ivo Mueller, Rhea Longley and Jessica Brewster of Walter Eliza Hall Institute of Medical Research, Australia, for their assistance in establishing the Luminex bead assay in Thailand and for their guidance on the antibody measurements.

\section{Authors' contributions}

$\mathrm{JH}$ planned and conducted all experiments, analyzed data, and was a major contributor in drafting the manuscript. AC prepared the RBP2P1 protein used in this study. JS guided the experiment and revised the manuscript. WN conceived of research, designed experiments, and was a major contributor in preparing the manuscript. All authors read and approved the final manuscript.

\section{Funding}

This work was supported by the Wellcome Trust (Grant 101073/Z/13Z to W.N.) and Faculty of Tropical Medicine (Mahidol University) Inbound Fellowship (to J.H.) The funders had no role in study design, data collection and analysis, decision to publish, or preparation of the manuscript.

\section{Availability of data and materials}

The datasets used and/or analyzed during the current study are available from the corresponding author on reasonable request.

\section{Declarations}

\section{Ethics approval and consent to participate}

The use of human specimens in this study was approved by the ethics committee of the Faculty of Tropical Medicine at Mahidol University. 


\section{Consent for publication}

Not applicable.

\section{Competing interests}

The authors declare that they have no competing interests.

\section{Author details}

${ }^{1}$ Department of Molecular Tropical Medicine and Genetics, Faculty of Tropical Medicine, Mahidol University, 420/6 Ratchawithi Road, Ratchathewi, 10400 Bangkok, Thailand. ${ }^{2}$ Mahidol Vivax Research Unit, Faculty of Tropical Medicine, Mahidol University, 420/6 Ratchawithi Road, Ratchathewi, 10400 Bangkok, Thailand.

Received: 24 March 2021 Accepted: 25 May 2021

Published online: 03 June 2021

\section{References}

1. McKenzie FE, Wongsrichanalai C, Magill AJ, Forney JR, Permpanich B, Lucas C, et al. Gametocytemia in Plasmodium vivax and Plasmodium falciparum infections. J Parasitol. 2006;92:1281-5.

2. Bousema T, Drakeley C. Epidemiology and infectivity of Plasmodium falciparum and Plasmodium vivax gametocytes in relation to malaria control and elimination. Clin Microbiol Rev. 2011;24:377-410.

3. Nguitragool W, Mueller I, Kumpitak C, Saeseu T, Bantuchai S, Yorsaeng $\mathrm{R}$, et al. Very high carriage of gametocytes in asymptomatic lowdensity Plasmodium falciparum and P. vivax infections in western Thailand. Parasit Vectors. 2017:10:512.

4. Beeson JG, Crabb BS. Towards a vaccine against Plasmodium vivax malaria. PLoS Med. 2007:4:e350.

5. Chan LJ, Dietrich MH, Nguitragool W, Tham WH. Plasmodium vivax reticulocyte binding proteins for invasion into reticulocytes. Cell Microbiol. 2020;22:e13110.

6. Cutts JC, Powell R, Agius PA, Beeson JG, Simpson JA, Fowkes FJ. Immunological markers of Plasmodium vivax exposure and immunity: a systematic review and meta-analysis. BMC Med. 2014;12:150.

7. Beeson JG, Kurtovic L, Dobano C, Opi DH, Chan JA, Feng G, et al. Challenges and strategies for developing efficacious and long-lasting malaria vaccines. Sci Transl Med. 2019;11:eaau1458.

8. Tham WH, Beeson JG, Rayner JC. Plasmodium vivax vaccine researchwe've only just begun. Int J Parasitol. 2017;47:111-8.

9. Franca CT, He WQ, Gruszczyk J, Lim NT, Lin E, Kiniboro B, et al. Plasmodium vivax reticulocyte binding proteins are key targets of naturally acquired immunity in young Papua New Guinean Children. PLoS Negl Trop Dis. 2016;10:e0005014.

10. Franca CT, White MT, He WQ, Hostetler JB, Brewster J, Frato G, et al. Identification of highly-protective combinations of Plasmodium vivax recombinant proteins for vaccine development. Elife. 2017;6:e28673.

11. Tran TM, Oliveira-Ferreira J, Moreno A, Santos F, Yazdani SS, Chitnis CE, et al. Comparison of IgG reactivities to Plasmodium vivax merozoite invasion antigens in a Brazilian Amazon population. Am J Trop Med Hyg. 2005;73:244-55

12. Gruszczyk J, Kanjee U, Chan LJ, Menant S, Malleret B, Lim NTY, et al. Transferrin receptor 1 is a reticulocyte-specific receptor for Plasmodium vivax. Science. 2018;359:48-55.

13. Chim-Ong A, Surit T, Chainarin S, Roobsoong W, Sattabongkot J, Cui $L$, et al. The blood stage antigen RBP2-P1 of Plasmodium vivax binds reticulocytes and is a target of naturally acquired immunity. Infect Immun. 2020;88:e00616-19.

14. Parker DM, Matthews SA, Yan G, Zhou G, Lee MC, Sirichaisinthop J, et al. Microgeography and molecular epidemiology of malaria at the Thailand-Myanmar border in the malaria pre-elimination phase. Malar J. 2015;14:198.

15. Bhumiratana A, Intarapuk A, Sorosjinda-Nunthawarasilp P, Maneekan P, Koyadun S. Border malaria associated with multidrug resistance on Thailand-Myanmar and Thailand-Cambodia borders: transmission dynamic, vulnerability, and surveillance. Biomed Res Int. 2013;2013:363417.

16. Putaporntip C, Hongsrimuang T, Seethamchai S, Kobasa T, Limkittikul $K$, Cui $L$, et al. Differential prevalence of Plasmodium infections and cryptic Plasmodium knowlesi malaria in humans in Thailand. J Infect Dis. 2009; 199:1143-50.

17. Nguitragool W, Karl S, White M, Koepfli C, Felger I, Singhasivanon P, et al. Highly heterogeneous residual malaria risk in western Thailand Int J Parasitol. 2019;49:455-62.

18. Longley RJ, Franca CT, White MT, Kumpitak C, Sa-Angchai P, Gruszczyk J, Hostetler JB, et al. Asymptomatic Plasmodium vivax infections induce robust IgG responses to multiple blood-stage proteins in a low-transmission region of western Thailand. Malar J. 2017;16:178.

19. Reiling L, Boyle MJ, White MT, Wilson DW, Feng G, Weaver R, et al. Targets of complement-fixing antibodies in protective immunity against malaria in children. Nat Commun. 2019;10:610.

20. Richards JS, Beeson JG. The future for blood-stage vaccines against malaria. Immunol Cell Biol. 2009;87:377-90.

21. Chan JA, Fowkes FJ, Beeson JG. Surface antigens of Plasmodium falciparum-infected erythrocytes as immune targets and malaria vaccine candidates. Cell Mol Life Sci. 2014;71:3633-57.

22. Beeson JG, Drew DR, Boyle MJ, Feng G, Fowkes FJ, Richards JS. Merozoite surface proteins in red blood cell invasion, immunity and vaccines against malaria. FEMS Microbiol Rev. 2016;40:343-72.

23. Longley RJ, White MT, Takashima E, Morita M, Kanoi BN, Li Wai Suen CSN, et al. Naturally acquired antibody responses to more than 300 Plasmodium vivax proteins in three geographic regions. PLoS Negl Trop Dis. 2017:11:e005888.

24. Longley RJ, White MT, Takashima E, Brewster J, Morita M, Harbers M, et al. Development and validation of serological markers for detecting recent Plasmodium vivax infection. Nat Med. 2020;26:741-9.

25. Ladeia-Andrade S, Ferreira MU, Scopel KK, Braga EM, Bastos Mda S, Wunderlich G, et al. Naturally acquired antibodies to merozoite surface protein (MSP)-1(19) and cumulative exposure to Plasmodium falciparum and Plasmodium vivax in remote populations of the Amazon Basin of Brazil. Mem Inst Oswaldo Cruz. 2007;102:943-51.

26. Lima-Junior JC, Tran TM, Meyer EV, Singh B, De-Simone SG, Santos $F$, et al. Naturally acquired humoral and cellular immune responses to Plasmodium vivax merozoite surface protein 9 in Northwestern Amazon individuals. Vaccine. 2008;26:6645-54.

27. Zakeri S, Babaeekhou L, Mehrizi AA, Abbasi M, Djadid ND. Antibody responses and avidity of naturally acquired anti-Plasmodium vivax Duffy binding protein (PVDBP) antibodies in individuals from an area with unstable malaria transmission. Am J Trop Med Hyg. 2011;84:944-50.

28. Yeom JS, Kim ES, Lim KJ, Oh JH, Sohn MJ, Yoo SB, et al. Naturally acquired IgM antibody response to the C-terminal region of the merozoite surface protein 1 of Plasmodium vivax in Korea: use for serodiagnosis of vivax malaria. J Parasitol. 2008;94:1410-4.

29. Walker KM, Okitsu S, Porter DW, Duncan C, Amacker M, Pluschke G, et al. Antibody and T-cell responses associated with experimental human malaria infection or vaccination show limited relationships. Immunology. 2015;145:71-81.

30. Morell A, Terry WD, Waldmann TA. Metabolic properties of IgG subclasses in man. J Clin Invest. 1970;49:673-80.

31. Kochayoo P, Kittisenachai N, Changrob S, Wangriatisak K, Muh F, Chootong $\mathrm{P}$, et al. The acquisition of long-lived memory $B$ cell responses to merozoite surface protein-8 in individuals with Plasmodium vivax infection. Malar J. 2019;18:188.

32. Park JW, Moon SH, Yeom JS, Lim KJ, Sohn MJ, Jung WC, et al. Naturally acquired antibody responses to the C-terminal region of merozoite surface protein 1 of Plasmodium vivax in Korea. Clin Diagn Lab Immunol. 2001;8:14-20.

33. Cheng Y, Wang B, Changrob S, Han JH, Sattabongkot J, Ha KS, et al. Naturally acquired humoral and cellular immune responses to Plasmodium vivax merozoite surface protein 8 in patients with $P$. vivax infection. Malar J. 2017;16:211.

34. Lim KJ, Park JW, Yeom JS, Lee YH, Yoo SB, Oh JH, et al. Humoral responses against the $\mathrm{C}$-terminal region of merozoite surface protein 1 can be remembered for more than 30 years in persons exposed to Plasmodium vivax. Parasitol Res. 2004;92:384-9.

35. Longley RJ, Reyes-Sandoval A, Montoya-Diaz E, Dunachie S, Kumpitak C, Nguitragool W, et al. Acquisition and longevity of antibodies to Plasmodium vivax preerythrocytic antigens in Western Thailand. Clin Vaccine Immunol. 2016:23:117-24. 
36. Kana IH, Garcia-Senosiain A, Singh SK, Tiendrebeogo RW, Chourasia BK, Malhotra P, et al. Cytophilic antibodies against key Plasmodium falciparum blood stage antigens contribute to protection against clinical malaria in a high transmission region of Eastern India. J Infect Dis. 2018;218:956-65.

37. Tiendrebeogo RW, Adu B, Singh SK, Dziegiel MH, Nebie I, Sirima $\mathrm{SB}$, et al. Antibody-dependent cellular inhibition is associated with reduced risk against febrile malaria in a longitudinal cohort study involving Ghanaian children. Open Forum Infect Dis. 2015;2:ofv044.

38. Kurtovic L, Boyle MJ, Opi DH, Kennedy AT, Tham WH, Reiling L, et al. Complement in malaria immunity and vaccines. Immunol Rev. 2020;293:38-56

39. Soe S, Theisen M, Roussilhon C, Aye KS, Druilhe P. Association between protection against clinical malaria and antibodies to merozoite surface antigens in an area of hyperendemicity in Myanmar: complementarity between responses to merozoite surface protein 3 and the 220-kilodalton glutamate-rich protein. Infect Immun. 2004;72:247-52.

40. Roussilhon C, Oeuvray C, Muller-Graf C, Tall A, Rogier C, Trape JF, et al. Long-term clinical protection from falciparum malaria is strongly associated with IgG3 antibodies to merozoite surface protein 3. PLoS Med. 2007;4:e320.

41. Versiani FG, Almeida ME, Melo GC, Versiani FO, Orlandi PP, Mariuba LA, et al. High levels of IgG3 anti ICB2-5 in Plasmodium vivax-infected individuals who did not develop symptoms. Malar J. 2013;12:294.
42. Changrob S, Han JH, Ha KS, Park WS, Hong SH, Chootong P, et al. Immunogenicity of glycosylphosphatidylinositol-anchored micronemal antigen in natural Plasmodium vivax exposure. Malar J. 2017; 16:348.

43. He WQ, Shakri AR, Bhardwaj R, Franca CT, Stanisic DI, Healer J, et al. Antibody responses to Plasmodium vivax Duffy binding and Erythrocyte binding proteins predict risk of infection and are associated with protection from clinical malaria. PLoS Negl Trop Dis. 2019;13:e0006987.

44. Kurtovic L, Behet MC, Feng G, Reiling L, Chelimo K, Dent AE, et al. Human antibodies activate complement against Plasmodium falciparum sporozoites, and are associated with protection against malaria in children. BMC Med. 2018;16:61.

45. Oyong DA, Wilson DW, Barber BE, William T, Jiang J, Galinski MR, et al. Induction and kinetics of complement-fixing antibodies against Plasmodium vivax merozoite surface protein 3alpha and relationship with immunoglobulin g subclasses and immunoglobulin M. J Infect Dis. 2019;220:1950-61.

\section{Publisher's Note}

Springer Nature remains neutral with regard to jurisdictional claims in published maps and institutional affiliations.
Ready to submit your research? Choose BMC and benefit from:

- fast, convenient online submission

- thorough peer review by experienced researchers in your field

- rapid publication on acceptance

- support for research data, including large and complex data types

- gold Open Access which fosters wider collaboration and increased citations

- maximum visibility for your research: over 100M website views per year

At BMC, research is always in progress.

Learn more biomedcentral.com/submissions 